\title{
Leopoldo María Panero, une figure rebelle dans la vision consensuelle de El País
}

\section{Chantal Chartier}

\section{(2) OpenEdition}

\section{Journals}

\section{Édition électronique}

URL : http://journals.openedition.org/agedor/537

DOI : 10.4000/agedor.537

ISSN : 2104-3353

Éditeur

Laboratoire LISAA

\section{Référence électronique}

Chantal Chartier, «Leopoldo María Panero, une figure rebelle dans la vision consensuelle de El País », L'Âge d'or [En ligne], 7 | 2014, mis en ligne le 01 mars 2014, consulté le 01 mai 2019. URL : http:// journals.openedition.org/agedor/537 ; DOI : 10.4000/agedor.537 
Chantal CHARTIER

Université Paris Est-IMAGER EA 3958

\title{
Leopoldo María Panero, une figure rebelle dans la vision consensuelle de E1 País
}

\begin{abstract}
Résumé : Le poète Leopoldo María Panero, l'un des Nueve novísimos, fils du poète Leopoldo Panero, a fait l'objet d'une attention particulière de la part des médias. Poète associé à la saga familiale des Panero médiatisée par plusieurs documentaires cultes, symbole de la génération du tardofranquisme et de la Transition démocratique, figure clé de la génération des poètes de 1968, Leopoldo María Panero a été présenté comme une personnalité sulfureuse et transgressive. Le journal El País évoque sa folie et sa radicalité, son lien avec les mouvements alternatifs, mais s'achemine néanmoins vers la reconnaissance du poète mythique. Le journal phare de la Transition démocratique et de la démocratie récupère dans une vision consensuelle la figure du poète maudit et canonisé, tout en gardant ses distances avec le personnage subversif.
\end{abstract}

Mots-clés : Leopoldo María Panero - El País - Médiatisation - Transgression - Consensus Novísimo - Transition démocratique

Resumen : El poeta Leopoldo María Panero, uno de los Nueve novísimos, hijo del poeta Leopoldo Panero, fue la comidilla de los medios de comunicación. Poeta asociado a la saga familiar de los Panero mediatizada por varios documentales de culto, símbolo de la generación del tardofranquismo y de la Transición democrática, figura clave de la generación de los poetas del 68, Leopoldo María Panero fue presentado como una personalidad sulfurosa y transgresora. El periódico El País evoca su locura y su radicalismo, su vínculo con los movimientos alternativos, pero se encamina sin embargo hacia el reconocimiento del poeta mítico. El periódico estrella de la Transición y de la democracia recupera en una visión consensuada la figura del poeta maldito y canonizado, pero guardando las distancias con el personaje subversivo.

Palabras clave : Leopoldo María Panero - El País - Mediatización - Transgresión - Consenso Novísimo - Transición democrática

Figure médiatisée et saga familiale

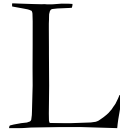

a vie de Leopoldo María Panero (1948-2014) a traversé l’Espagne franquiste, la Transition démocratique et l'Espagne démocratique. Poète dit maudit, figure transgressive de la littérature espagnole, Leopoldo María Panero est désormais reconnu comme l'un des plus grands poètes espagnols des $\mathrm{XX}^{\mathrm{e}}$ et $\mathrm{XXI}^{\mathrm{e}}$ siècles. Mais en a-t-il toujours été ainsi ? Si l'on considère la réception de son œuvre par le journal El País, il nous est donné d'observer une évolution quant au traitement de l'information le concernant. Analyser cette réception par le prisme de ce journal créé en 1976, au plus fort de la Transition démocratique espagnole, et devenu journal de référence de l'Espagne 
démocratique nous permet de saisir les évolutions sociétales et culturelles à l'œuvre lors de ces décennies comme le positionnement du journal face à ce poète dit radical. El País, journal qui a accompagné l'ouverture culturelle après la chape de plomb du franquisme, estil le défenseur d'une poésie radicale et dérangeante, ou se contente-t-il de récupérer cette figure transgressive au profit d'un discours lénifiant? De même que le journal a su d'une certaine manière être au diapason des mouvances culturelles en récupérant la contreculture, on peut se demander si, pour El País, adopter le point de vue des thuriféraires du poète n'entre pas finalement dans une vision consensuelle.

Figure médiatisée par la saga familiale des Panero, symbole d'une génération (1968 et Transition), Leopoldo María Panero est entré dans l'Histoire espagnole et dans l'Histoire littéraire.

C'est avant tout le personnage que retiennent les pages de El País. Dans la célèbre chronique de Francisco Umbral, Diario de un snob, l'auteur évoque sous le titre «El neodestape » le film réalisé par Jaime Chávarri sur la famille Panero, El desencanto. La chronique de Umbral s'inscrit dans le contexte de ce que l'on a appelé le destape faisant référence à la levée des barrières morales sur la nudité et au-delà, à la libéralisation des mœurs à l'œuvre au début de la Transition démocratique. Umbral évoque ce film comme l'illustration de ce que les représentants de l'Église catholique nomment la crise de la famille, et le relie, tout en le distinguant, à la vague d'érotisme ou de pornographie commerciales qui envahit l'Espagne. Mais le film est une forme de mise à nu différente, ce que suggère aussi le titre neodestape ${ }^{1}$, celle des relations familiales, marquées aussi par le franquisme et par la figure du père poète, Leopoldo Panero.

Ce film, auréolé de rumeur scandaleuse, est lié intimement à la figure de Leopoldo María Panero, personnage plutôt fantasque si l'on en croit le discours du journal, qui s'attarde plus volontiers sur la personne que sur l'œuvre, et qui évoque la publication de En lugar del bijo dans sa rubrique Société :

El joven poeta y enfant terrible de nuestras letras, que protagonizaba realmente El desencanto, esa película de Chávarri que ha sembrado el escándalo y la sorpresa, acaba de publicar un libro de cuentos : En lugar del bijo. El otro día, a la salida misma de la Editorial Tusquets, y tras recibir los « ejemplares de autor», se cuenta que Leopoldo María los repartió, hasta el último, entre la gente que pasaba por la calle ante la sorpresa de los transeúntes. ${ }^{2}$

Le décès en 1990 de Felicidad Blanc, écrivaine et veuve du poète Leopoldo Panero, donne lieu à l'évocation de l'internement psychiatrique de Leopoldo María Panero. La disparition de la mère est de nouveau prétexte à un étalage de la vie privée de la famille, dans la section Gente. Après avoir relaté les noces de Felicidad Blanc, il est fait allusion, de manière presque feuilletonesque, à sa relation avec le poète Luis Cernuda, qui aurait mis le couple en difficulté. L'article juge le film de Chávarri d'une très grande dureté et mentionne la publication en 1977 des mémoires de l'écrivaine, Espejo de sombras, "complemento personal y escrita con una sinceridad transparente", según la autora, con El desencanto » ${ }^{3}$.

\footnotetext{
1 «Ayer vi en pase privado El desencanto, interesante película de Jaime Chávarri sobre la familia Panero. La familia está en crisis, como dicen los curas, acertando como si no fueran curas, pero la familia se defiende aún ante esta marca alta de pornografía, bajamente comercial, que ahora mismo disfrutamos. Es la ola -deerotismo-que-nos-invade, sí. », UMBRAL, Francisco, «El neodestape », El País, 22/8/1976, http://elpais.com/diario/1976/08/22/sociedad/209512803_850215.html, [20/3/2013]. 2 «Leopoldo María Panero », El País, 13/1/1977, http:/ / elpais.com/diario/1977/01/13/sociedad/221958012_850215.html, [20/3/2013]. 3 « Felicidad Blanc, escritora y viuda de Leopoldo Panero », El País, 2/11/1990,
} 
La famille ne cesse d'intéresser les réalisateurs et le public. En 1993, Ricardo Franco annonce le tournage d'un documentaire, Después de tantos años, dans un article de El País, publié cette fois dans la section culturelle: "Ricardo Franco rueda una película sobre la conflictiva familia del poeta ${ }^{4}$, le mot poète faisant référence à la figure du père :

En 1975 el cineasta Jaime Chávarri hizo la película El desencanto, donde retrataba a la familia del ya por entonces fallecido poeta Leopoldo Panero. Sus tres hijos, Juan Luis, Leopoldo María y Michi y su viuda, Felicidad Blanc, recorrían despiadadamente sus asfixiantes recuerdos familiares. Hoy, casi veinte años después, otro cineasta, Ricardo Franco, vuelve a poner frente a una cámara, ya muerta la madre, a los tres hermanos. "No somos una familia y no sé exactamente lo que quiero contar" dice Juan Luis Panero. Su hermano, Leopoldo María, añade: "Yo quiero contar la historia de un linchamiento, el mío". Y Michi afirma. "Será una película sobre la ruina".

Après le décès de leur mère, les trois frères témoignent de manière séparée et reviennent sur la destruction de la famille. El País insiste sur la maladie mentale de Leopoldo María : «poeta como su padre [...] desde el sanatorio para enfermos mentales de Mondragón, en Guipúzcoa, (donde está internado desde hace más de cinco años) [...]»" Le poète interné préfigure sa fin à l'image de celle d'un jouisseur martyr : "Y añade : "Mi final es como el de Casanova en la película de Fellini : le puteaban e insultaban por la calle y mientras comía" " ${ }^{7}$. L'éloge de la mère s'accompagne d'une diatribe antipolitique dans une posture victimiste :

Leopoldo María Panero, que recuerda que en este filme no estará su madre, Felicidad Blanc : "No pudieron conmigo y la atacaron a ella. Todo es por culpa de la política que, tanto la de izquierdas como la de derechas, es aún más sucia que la locura". [...] "Ella", continúa el poeta, era más vulnerable que yo, era una maravilla de persona, muy guapa y muy sensible". "Cuando mi madre murió me quedé solo y todavía no me acostumbro a estar sin ella", termina. ${ }^{8}$

Au-delà de l'intérêt purement médiatique, aux accents mélodramatiques, que suscite cette famille se profile finalement le portrait d'une génération, de ses illusions et espoirs, de ses désillusions et drames, marqué par la fin de l'utopie. Le réalisateur Ricardo Franco le souligne :

Dice el director Ricardo Franco para presentar su película : ¿Qué ha sido de ellos desde entonces? $\mathrm{O}$, lo que viene a ser lo mismo, ¿qué ha sido de todos nosotros? ¿Qué de nuestros sueños y de nuestras ilusiones?"

$\mathrm{Y}$ añade: "Después de tanto años es un intento de observar con rigor, pero no por ello prescindiendo de una pasión necesaria, lo que el paso de casi veinte años ha causado en estas tres personas que, siendo singulares, por ello pueden resultar paradigmáticas de tantos que

http://elpais.com/diario/1990/11/02/agenda/657500401_850215.html, [20/3/2013].

${ }^{4}$ FERNÁNDEZ-SANTOS, Elsa, «Los Panero se enfrentan a un nuevo desencanto », El País, 1/7/1993, http://elpais.com/diario/1993/07/01/cultura/741477606_850215.html, [20/3/2013].

${ }^{5}$ Ibid.

${ }^{6}$ Ibid.

${ }^{7}$ Ibid.

${ }^{8}$ Ibid. 
creyeron que se podía cambiar el mundo tan sólo con pedir lo imposible, y que tantas bajas ha dejado en el camino". 9

C'est aussi l'opinion de l'écrivaine Soledad Puértolas, exprimée dans un article de El País consacré à la sortie du film, «El regreso cruel de los Panero »" qui considère la vie de la famille Panero comme un miroir de sa génération, même si elle nuance cette vision paradigmatique par les termes 'miroir déformant' dans le cas des frères Panero :

La escritora Soledad Puértolas recuerda todavía la impresión que le causó El desencanto. "Lo de menos fue que fueran los Panero, eso no pasaba de ser una anécdota o un símbolo; lo importante es que por primera vez veíamos lo que sospechábamos : las dramáticas relaciones familiares confesadas abiertamente". [...] "Aunque sin llegar quizás a los extremos de los hermanos Panero, todos los de mi generación hemos atisbado algo de esa vida intensa y destructora. Es como un espejo deformante de lo que somos, en el que te identificas y que te estremece", relata la escritora. ${ }^{11}$

El desencanto était présenté comme une dissection cruelle de la famille du poète Leopoldo Panero, évoqué comme le poète du franquisme par El País. Le film Después de tantos años est le bilan générationnel de jeunes sans futur selon Chávarri : "Se notan mucho, demasiado, esos veinte años. Como dice Jaime Chávarri, El desencanto era un melodrama en el que unos jóvenes, con un futuro sin posibilidades, hablaban de su pasado, y en el nuevo filme se ve que ya no tienen futuro $»^{12}$.

L'écrivain Vicente Molina Foix, qui fut l'ami intime de Leopoldo María, parle de naufrage de cette famille, mais encense la vertu cathartique de ce type de documentaire face à la pruderie de la société espagnole :

De naufragio habla el escritor y crítico Vicente Molina Foix. "Del naufragio de El desencanto hemos pasado a los restos del naufragio : los tres náufragos en una isla desierta", dice Molina Foix, que echa de menos en Después de tantos años la ausencia de la madre, pero se alegra de ver cómo se desnudan en público tres personas "en una sociedad tan pacata como la nuestra". ${ }^{13}$

Malgré la représentation du désastre, l'auteur de l'article de El País préfère terminer, de manière lénifiante, sur une note d'espoir suggérée par le film selon Soledad Puértolas: «Pero junto a la ruina anida la esperanza. El vitalista Ricardo Franco lo ha lanzado y Soledad Puértolas lo ha recogido. "La conclusión del filme es absolutamente esperanzadora. Se refleja en el tambaleo al caminar de Michi, quien, a pesar de todo, se agarra a la vida" $»^{14}$.

Les Panero continueront de défrayer la chronique... En 1996, une émission télévisée spéciale exhume de nouveau les misères familiales avec la programmation des deux documentaires, que El País présente en reprenant les termes de Molina Foix : "Canal+

\footnotetext{
${ }^{9}$ Ibid.

${ }^{10}$ GARCÍA BEATO, Rocío, «El regreso cruel de los Panero », El País, 10/2/1995, http://elpais.com/diario/1995/02/10/ultima/792370802_850215.html, [20/3/2013].

${ }^{11}$ Ibid.

12 Ibid.

${ }^{13}$ Ibid.

${ }^{14}$ Ibid.
} 
dedica su noche al naufragio de los Panero $»^{15}$. L'accent est mis sur le déchirement de la famille, mais aussi sur le caractère polémique qui a entouré ces documentaires dont la dimension historique et originale est soulignée. Toutefois les accroches voyeuristes ajoutent une note de spectacularisation. On retient du poète Leopoldo María, son homosexualité et sa folie, de Juan Luis son passé communiste et de Michi son alcoolisme. La figure du père est associée au franquisme et au fascisme:

Esta noche, Canal+ abre una vieja herida, la de la familia Panero, en una sesión doble de cine contracorriente, intenso, poético y polémico : El desencanto (1976), de Jaime Chávarri, y Después de tantos años (1994), de Ricardo Franco. Documentos de una familia desgarrada, ambas películas suponen sendas experiencias originales en una cinematografía poco dada al riesgo. Por primera vez, una televisión las emite seguidas, permitiendo al espectador escarbar en la dolorosa memoria de unos personajes reales cuyas vidas, cuyas tragedias, rozan la fantasía onírica, casi la pesadilla. El desencanto reunía a la familia Panero tras la muerte del patriarca, Leopoldo Panero, poeta oficial del régimen franquista. La idea, originalmente concebida para un cortometraje, acababa por generar un intenso y brutal exorcismo conducido por la viuda, Felicidad Blanc, y sus hijos : Leopoldo María, poeta homosexual sacudido por la locura ; Juan Luis, poeta y crítico ex comunista, y Michi, escritor macerado en horas de alcohol. Las cuatro figuras confiesan a cámara sus odios, sus recelos, sus angustias, sus particulares venganzas a la figura paterna, a la presión fascista. ${ }^{16}$

L'auteur de l'article revendique le caractère mémoriel de ces documentaires pour tous les Espagnols, tout en les qualifiant de ciné-vérité : «Esta sesión doble de cine-verite obliga al espectador a contemplarse en un espejo. Las dos décadas transcurridas entre El desencanto y Después de tantos años no sólo han sacudido los cimientos emocionales del [clan de los] Panero ; también han horadado las ilusiones de un país desquiciado $»^{17}$.

Présenté comme objet médiatique à la limite de la télé-réalité ( L La familia salta a escena en este aplaudido docudrama ${ }^{18}$, « un intenso docudrama lleno de reflexiones sobre la institución familiar. Los hijos y la mujer del poeta Leopoldo Panero muestran sus experiencias en esta amarga y divertida curiosidad del cine español. Diferente. ${ }^{19}$ ) et comme documentaire dramatique et document historique mémoriel, El desencanto sera reprogrammé de nombreuses fois.

En 2009, un nouveau documentaire, Los abanicos de la muerte, tente de réhabiliter la figure du poète Leopoldo Panero. C'est l'occasion de rappeler ce que fut la réception de El desencanto: "Muchos ven en esta película una metáfora de la decadencia del régimen franquista. Otros al precursor de los actuales reality show: personajes enfrentados sobriamente a la cámara relatando sus miserias $»^{20}$.

À l'occasion de la présentation du film, El País revient sur la cinématographie de cette famille de "poètes maudits » et explique l'intention du cinéaste Luis Miguel Alonso

\footnotetext{
15 ALBERT, Antonio, "Canal+ dedica su noche al naufragio de los Panero », El País, 22/2/1996, http://elpais.com/diario/1996/02/22/radiotv/824943601_850215.html, [20/3/2013].

${ }^{16}$ Ibid.

${ }^{17}$ Ibid.

18 MORALES, Fernando, «El desencanto », El País, 19/10/1997, http://elpais.com/diario/1997/10/19/radiotv/877212018_850215.html, [ 20/3/2013].

${ }^{19}$ MORALES, Fernando, «El desencanto », El País, 22/3/1998, http://elpais.com/diario/1998/03/22/radiotv/890521210_850215.html, [20/3/2013].

${ }^{20}$ FANJUL, Sergio C., "Los abanicos de la muerte », nueva mirada a los Panero », El País, 18/9/2009, http://elpais.com/diario/2009/09/18/cine/1253224801_850215.html, [20/3/2013].
} 
Guadalupe de redonner la parole au poète Leopoldo Panero, peut-être injustement traité dans El desencanto et déjà en voie de réhabilitation dans Después de tantos años :

El Desencanto (1976), de Jaime Chávarri, fue, según Alonso Guadalupe, la película de la transición española, pero en ella las diferencias familiares no permitieron llegar a conocer en profundidad al propio escritor, una personalidad compleja : fue preso de Franco, pero luego viró hacia posturas favorables al dictador, siempre conservando una obra poética de calidad indiscutida. Su figura volvió a ser revisada en 1995 con el filme Después de tantos años, de Ricardo Franco, aunque esta película se centra más en la figura de Leopoldo María Panero, quizá el poeta más sobresaliente de la familia. [...]

Para el director de la nueva película, no se está haciendo un contra-Desencanto, sino "algo complementario, donde bucearemos en el propio Panero, con unas pinceladas sobre el poeta, lo que escribió, sus versos y poemas, su vida, su etapa comunista y su prisión...". ${ }^{21}$

C'est finalement la portée littéraire qui semble justifier l'intérêt pour les personnages en tant que poètes d'exception, que sont Leopoldo Panero et Leopoldo María Panero, réunis en photo ${ }^{22}$ par El País.

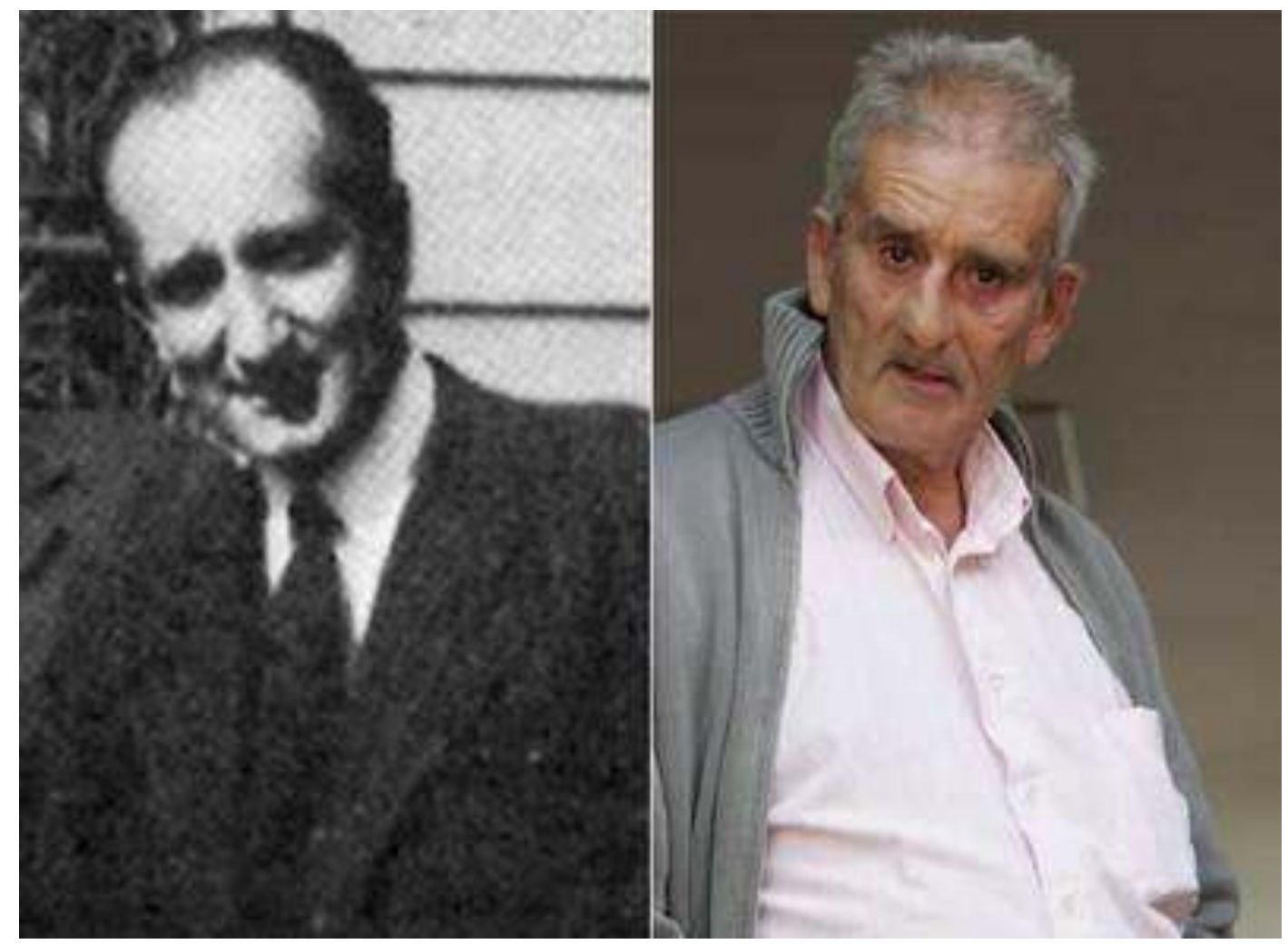

A la izquierda Leopoldo Panero, a la derecha, su hijo Leopoldo María Panero / RESIDENCIA DE ESTUDIANTES / LUIS MAGÁN

21 «Los Panero, de nuevo bajo la lupa del cine », El País, 4/8/2009, http://cultura.elpais.com/cultura/2009/08/04/actualidad/1249336802_850215.html, [20/3/2013]. 22 Ibid. 
Leopoldo María Panero semble vivre cette médiatisation de manière assez ambiguë. Son attitude d'exilé volontaire de la société peut laisser penser qu'il recherche cette exclusion pour se protéger. D’un côté, il vitupère l'irruption des médias dans sa vie privée, si l'on en croit son cri lancé dans le Courrier des lecteurs de El País, cri qui éreinte l'Espagne chrétienne et critique les séquelles de la dictature franquiste sur l'État dit démocratique, dans une vision dystopique; de l'autre, il semble goûter cette position de victime expiatoire ou de nouveau Dreyfus :

Harto como estoy de las graves intromisiones desde los locutorios de RTVE en mi vida privada, y al margen de la locura que aún queda para defenderla, me veo obligado a resolver este problema, que consiste en los residuos de un escándalo ya pasado por los frágiles medios de que dispongo. El hecho es que estos locutores tienen el poder de mi nombre y que el silencio movilizado sobre un caso Dreyfus, y sin más Zola que yo mismo por intermedio de la muerte y de la solidaridad humana más bestial con ella y con sus cómplices, me hace pensar que sólo me quede la aceptación de esas vejaciones. En este país se ve que el cristianismo - $\tan$ alabado en las preces- tiene en la realidad de este país poquísima fortuna : sin embargo, la creencia en Cristo y en los milagros es el estado anímico a que conduce la tortura.

Otras raíces de esta cuestión son los restos de la dictadura paternalista-fascista que configura el Estado como un defensor del pueblo indefenso, esto es, sin voz -como de hecho no tiene-, dictadura que al parecer envía sus aparatos de Estado en defensa de sus ruinas, acusándome de terremotos y de asesinatos, y sin tener otra ficha policial de mí -y esto es lo más grave- que la de "monstruo, asesino", etcétera, tal como el mismo pueblo indefenso se armó para decirlo. $^{23}$

En 1994, El País évoque un programme radiophonique sur la SER qui donne la parole à cinq "malades mentaux», et auquel participe bien volontiers Leopoldo María Panero, et le journal insiste sur un certain voyeurisme des auditeurs :

Todos los jueves, Leopoldo María Panero sale del manicomio de Mondragón (Guipúzcoa) para participar, con otros cuatro enfermos mentales más, en la tertulia de La ventana, el programa que conducen Javier Sardà y el señor Casamajor en la cadena SER. [...] "Cuando alguno cuenta cómo ha sido su electrochoque, por ejemplo, el interés de los oyentes aumenta", comenta Javier Sardà. ${ }^{24}$

Au-delà de la représentation de Leopoldo María Panero indissolublement liée à la folie et à la saga familiale marquée par la destruction, c'est la représentation du poète marginal et maudit qui domine, mais en lien avec l'évolution des moeurs qui commence à secouer l'Espagne. Si la notoriété médiatique obère quelque peu l'écriture du poète, celui-ci acquiert cependant une reconnaissance qui va se confirmer au fil du temps au point de devenir le «poète mythique ».

\section{Le poète marginal : poète fou et intellectuel érudit, poète maudit et canonisé}

\footnotetext{
23 PANERO, Leopoldo María, "RTVE en la vida privada », Cartas al Director, El País, 14/9/1986, http://elpais.com/diario/1986/09/14/opinion/527032803_850215.html, [20/3/2013].

24 «El otro lado de la realidad», El País, 12/2/1994, http://elpais.com/diario/1994/02/12/radiotv/761007601_850215.html, [20/3/2013].
} 
Umbral, dans sa chronique Diario de un snob, associait déjà, en 1977, le jeune poète à Baudelaire : « un Baudelaire que Madrid no tiene (a no ser que lo sea ese Leopoldo María Panero de madrugada, hijo pródigo de Felicidad Blanc) $»^{25}$. La figure de Leopoldo María Panero est aussi celle de l'intellectuel engagé sur les questions de société : homosexualité, féminisme, psychanalyse, et proche d'un certain militantisme radical. En 1977, une conférence de Leopoldo María Panero est évoquée dans El País, lors de la présentation de son livre En lugar del hijo, conférence suivie d'un colloque réunissant une féministe, Cristina Valverde, le psychanalyste argentin lacanien, Jorge Alemán et Juan Manuel Bonet, poète et critique d'art.

El discurso circuló fundamentalmente en torno al tema de la escisión de los sexos que, según Panero, fundamenta la separación del cuerpo y el discurso y, por tanto, de la sociedad y la escritura. Escisión original que inaugura todas las ulteriores. Ya que tanto el proletariado como la juventud, como los homosexuales, como las mujeres, como los «locos», padecen un mismo estigma corporal. Redefinición de proletariado que venía a ser como propuesta y conclusión del discurso. ${ }^{26}$

En 1979, un article de El País évoque un colloque à l'Université Complutense de Madrid consacré à «la question homosexuelle », lors duquel un représentant du Front de Libération Homosexuelle de Castille explique que les marginaux sont l'espérance révolutionnaire, et Leopoldo María Panero de dénoncer l'hypocrisie morale : "Leopoldo María Panero habló de la escisión entre lo privado y lo público y de la hipocresía moral ${ }^{27}$.

La figure de Leopoldo María Panero est également associée à l'art alternatif; il participe au Festival Indépendant de Madrid, Festimad, haut lieu de la «culture minoritaire $»^{28}$, qui propose un récital de poésie, Poética ${ }^{29}$. La vitalité de cette poésie y est soulignée même si l'association avec le sexe et la drogue constitue une accroche de la part de El País:

Sexo, drogas y fantasía poética. Ésos son los principales ingredientes de los poemas que han presentado durante dos días la veintena de escritores que han intervenido en el festival Poética, organizado por Festimad. Lejos de academicismos o campañas editoriales, la programación de este certamen ha tenido el interés de revelar libremente las formas en que viven la poesía actual tanto los jóvenes como sus maestros en independencia de espíritu. ${ }^{30}$

La poésie indépendante revendique ses liens avec les générations rock, beat, avec 1968. El País présente Leopoldo María Panero comme l'un des personnages emblématiques de ce récital, l'un des maittres de la transgression, en évitant cependant toute citation dérangeante ou subversive :

\footnotetext{
25 UMBRAL, Francisco, « Doña Cocolito », Diario de un snob, El País, 24/11/1977, http://elpais.com/diario/1977/11/24/sociedad/249174005_850215.html, [20/3/2013].

26 « Hacia una redefinición del Proletariado », El País, 25/1/1977, http://elpais.com/diario/1977/01/25/cultura/222994802_850215.html, [20/3/2013].

27 «Coloquio en la Universidad sobre ' la cuestión homosexual '», El País, 24/1/1979, http://elpais.com/diario/1979/01/24/sociedad/285980420_850215.html, [20/3/2013].

${ }^{28}$ FERNÁNDEZ-SANTOS, Elsa, « Madrid se convierte en capital del arte alternativo », El País, 2/5/1996, http:/ /elpais.com/diario/1996/05/02/madrid/831036276_850215.html, [20/3/2013].

${ }^{29}$ JARQUE, Fietta, «La poesía independiente muestra su vitalidad en el festival Poética », El País, 18/5/96, http://elpais.com/diario/1996/05/18/cultura/832370404_850215.html, [20/3/2013].

${ }^{30}$ Ibid.
} 
Leopoldo María Panero, uno de los maestros transgresores que dieron lustre a la programación, desgranó unos poemas inéditos de su nuevo libro, Poemas de la vieja, llenos de amarga ironía fantasmagórica. En resumen, un estimulante programa, variado en forma y fondo, un atentado contra la rigidez de un arte que a veces parece anquilosado, pero que a veces también sabe demostrar su inmortal frescura. ${ }^{31}$

Dans un autre article consacré à Festimad, "Poética reúne a varias generaciones de poetas radicales ${ }^{32}$, El País insiste sur la diversité, l'indépendance, le risque, le lien avec les vieux rockers et la génération beat, sur le mélange des genres, qui n'est pas sans rappeler la culture de la Movida:

Festimad concluye la intensa y variada programación que ha presentado este año con una iniciativa arriesgada, un festival de poesía que reúne a importantes figuras de la lírica internacional unidas por un solo hilo : su independencia. Viejos rockeros como John Cale y Tav Falco, poetas españoles de distintas generaciones, como Agustín García Calvo y Leopoldo María Panero, [...] forman parte de un cartel de indudable interés. [...]

"El cartel muestra las estrechas vinculaciones entre el rock y la poesía, porque pensamos que éstas (sic) han estado unidas desde siempre", dice Ana Curra, una de las organizadoras del festival. "Creemos que así llegará a mucha más gente porque en el rock ha habido grandes poetas que con sus letras lograban proyectar sensaciones intensas, descolocarte, movilizarte, encogerte. [...] No nos interesan los literatos engolados, vacíos y retóricos". [...] "La poesía no tiene edad", insiste Curra. [...] "serán recitales en los que los medios de expresión varían. La británica Lydia Lunch vendrá con un guitarrista, John Giorno traerá un audiovisual, Mario Zorrilla ha hecho un montaje teatral con poemas de El Ángel, Mohamed Hamri trae un corto en super 8 sobre los Master Musicians of Jojouka, Corcobado viene con un pianista, los Islamic Diggers rapearán y Gonzalo Rojas leerá sus poemas”, explica Ana Curra.

La construction de la figure du poète dans le discours de El País s'affine pour évoquer avec plus de soin son écriture et sa création. Une attention particulière est accordée à la rencontre avec le poète italien Claudio Rizzo, à leur amitié naissante et à la création de leur poème à deux voix, Tensó :

Dos hombres unidos por la soledad acaban de conocerse. [...] Entre ambos suman cientos de poemas publicados, pero casi nadie los conoce por eso. Antes de la cita, Rizzo sólo sabe de Panero por la lectura de Locos : "Cuando lo leí, enseguida quise conocer a aquel tipo que en cierto modo me recordaba a mí mismo. Le llamé y me presenté en Mondragón”. La idea es embarcarse en una tensó, palabra provenzal que define una lucha dialéctica entre dos o más poetas, ver lo que sale y tratar de publicarlo. O no..$^{33}$

Sous le sous-titre "obscurité et richesse ", c'est un Panero différent qui émerge, loin de la folie, même s'il vit dans un asile psychiatrique, auteur avec Rizzo de vers « inquiétants » que traversent des « images insolites »:

“ [...] estábamos metidos en una lucha por ver quién era más oscuro y más rico", dice ahora

Panero entre interferencias, largos silencios y llamadas de los enfermeros de Santa Águeda

31 Ibid.

32 «Poética reúne a varias generaciones de poetas radicales », El País, 16/5/1996, http://elpais.com/diario/1996/05/16/madrid/832245869_850215.html, [20/3/2013].

33 MORA, Miguel, "Tensó: poema a dos voces en el abismo », El País, 9/4/1997, http://elpais.com/diario/1997/04/09/cultura/860536810_850215.html, [20/3/2013]. 
para que acuda a comer. "Trabajamos en medio de un frío perro, rodeados de locos. Pero de locos auténticos, no como Leopoldo, que es afectivamente desequilibrado pero en absoluto loco", explica Rizzo desde Las Palmas. El resultado de esos días al lado del abismo, escribiendo y callando entre bromas y vasos es Tensó [...]. Poema a dos voces que son en realidad una, anda lleno de imágenes insólitas, versos inquietantes y preguntas como ésta : ¿Por qué los hombres lloran? ¿No es peor el silencio? / ¿No es peor que la barba y su sonrisa búmeda de borrachos / que escupen sobre el poema y arden en la hoguera feroz / de la nada en donde Dios embiste con usura...?34

Rizzo évoque la tendresse et l'humour de son ami poète. Leopoldo María Panero luimême nie sa folie: "Si es que yo de loco no tengo nada" se irrita Panero. [...] y ya ni siquiera declara creer en la locura : "Pensaba que los locos eran santos, los crónicos sobre todo, porque han soportado duchas, electrochoques, tipos diciéndoles 'sácate la mierda de la cabeza'... Ahora sé que cuanto más sufre uno, más hijo de puta es" »" ${ }^{35}$. Si le côté obscur du poète et de sa famille est ressassé ("Hijo del conocido poeta falangista del mismo nombre, Leopoldo Panero, ha vivido desde joven en el lado oscuro: rodeado de psiquiatras, pastillas [...], poemas y películas como El desencanto 1 y 2 , testimonios de la decadencia de una familia ilustrada $»)^{36}$, le poète n'en est pas moins glorifié au travers de l'évocation de son écriture et de son activité culturelle intense. El País s'autorise même des citations, peu transgressives cependant :

Pero al mismo tiempo, sorprendentemente, sigue trabajando con dedicación de monje. Escribe poemas solo -La visita se ha ido, / quedan sobre la mesa pétalos de ceniza-; dicta conferencias -"ahora doy una sobre elegías medievales, eso tan gracioso que narraba cómo el Espíritu Santo le entraba a la Virgen por la oreja”- ; redacta textos antipsiquiátricos, está a punto de publicar una obra de teatro titulada Carne vale y habla en la radio. ${ }^{37}$

Pourtant Rizzo et Panero revendiquent la transgression, dans leur vie et dans leur écriture poétique :

El genovés dice que "la cosa funcionó porque teníamos muchas cosas en común : los dos hemos vivido radicalmente, lejos de las normas, los dos creemos en la poesía como transgresión, y los dos rompemos la tradición española : preferimos La tierra baldía, de Eliot, a la generación del 27, estamos más cerca de Dylan Thomas que de Lorca”.38

Son départ de l'asile de Mondragón, où il a subi pendant huit ans une discipline militaire, pour Las Palmas de Gran Canaria à l'invitation de Rizzo est salué par El País comme une remise en lumière : «El sol después de la niebla; el poeta Leopoldo Panero cambia el manicomio de Mondragón por la luz de Canarias $"{ }^{39}$. Le poète n'apparaît plus seulement dans le discours de El País sous le signe de la marginalité, il retrouve la place qui a été la sienne, dès le départ, au sein du groupe des novísimos ${ }^{40}$, comme l'un des plus brillants jeunes poètes de cette génération. El País se laisse aller aux nombreux superlatifs : «Panero, para muchos el poeta más moderno y brillante de los de su generación de novísimos », «el

${ }^{34}$ Ibid.

${ }^{35}$ Ibid.

${ }^{36}$ Ibid.

${ }^{37}$ Ibid.

${ }^{38}$ Ibid.

${ }^{39}$ SCHEUERMANN, Stefan, «El sol después de la niebla », El País 31/7/1997, http://elpais.com/diario/1997/07/31/ultima/870300001_850215.html, [20/3/2013].

${ }^{40} \mathrm{Du}$ nom de l'anthologie de José María Castellet, Nueve novísimos poetas españoles, publiée en 1970. 
excelente poemario Tensó » ${ }^{41}$. La place donnée aux propos du nouveau psychiatre, Rafael Inglott Domínguez, présenté comme un professionnel progressiste, citant Artaud et Joyce, donne une dimension culturelle indéniable à l'article qui sous-tend une très haute image du poète :

Inglott, que, además de ser médico progresista ha escrito algún relato, está convencido del carácter terapéutico de la creación literaria : "Sería deseable que la psiquiatría no tuviera que intervenir, porque la literatura no sólo guarda una estrecha relación con la locura, sino que puede perfectamente estabilizar al psicótico. Existen numerosos casos, como Antonin Artaud o James Joyce, por poner dos ejemplos. No dudo de que la literatura haya hecho mucho más por Leopoldo María Panero que la psiquiatría." ${ }^{\text {42 }}$

Sans abandonner un certain ton people, l'article évoque Ezra Pound et T. S. Eliot, et cite les vers de Rizzo/Panero :

Los primeros contactos de Panero con la sociedad canaria se dieron en la terraza de un hotel de lujo desde la que contempló la puesta de sol frente a la playa de las Canteras. Una vez aburridos de tanta belleza y cansados de reír y de jugar a sentirse reencarnaciones de dobles personalidades como "Laurel y Hardy, el gordo y el flaco, o de Ezra Pound y T. S. Eliot", Leopoldo y Claudio no tardaron en hacer versos para su Tensó 2, que ya han empezado a inventar y del que adelantamos el siguiente fragmento :

El bumo de la locura / que en la boca semeja el cigarro, / que en la boca muestra una moneda/ ofrecida a los dientes del poema, / abora penetra tu sexo, / quema el mio, / todo arde y hasta lo oscuro baja hasta el suelo. / Queda la colilla del poema / escrito con la mano quemada. Y tan bien escrito. ${ }^{43}$

C'est le poète hypersensible et excentrique qui émerge au détriment de la figure du fou ou de celle du poète maudit, toutes deux contestées par J. Benito Fernández, lorsqu'il publie sa biographie, El contorno del abismo ( El biógrafo de Leopoldo M. Panero pone en duda la locura del poeta $\left.{ }^{44}\right)$. Les références à la saga familiale n'occultent plus le poète novísimo ni son mentor, Pere Gimferrer :

Treinta años de manicomio en manicomio, una leyenda negra de príncipe de los excesos y de poeta y personaje siempre al borde, y resulta que su biógrafo y sus psiquiatras dudan seriamente de que esté loco. Pero así es Leopoldo María Panero, un tipo inclasificable, un poeta más que cualquier otra cosa.

El libro [...] cuenta [...] la vida, excesos y milagros de uno de los hijos más rabiosos y subversivos de la cultura española. El relato empieza en los setenta, cuando Panero (Madrid, 1948) es ya el excéntrico número uno de la vida nocturna madrileña ; [...] "Por casualidad, encontré a una persona en Ibiza que guardaba cientos de cartas de la familia”. [...] algunas de su madre, Felicidad Blanc, "con quien mantenía una relación amor-odio aterradora" otras de su padre, Leopoldo Panero, "injustamente llamado el poeta del régimen”, y sobre todo, la correspondencia que el poeta mantuvo con el escritor Pere Gimferrer. "Leopoldo lo consideró siempre su maestro, el maestro de toda su generación. Le consultaba todo, tenía una fe ciega en él", comenta. [...] Niega el malditismo del poeta. "Los malditos no hablan en la radio, no publican, no salen en la tele". Y duda abiertamente sobre su locura : "Saca dinero

\footnotetext{
${ }^{41}$ SCHEUERMANN, Stefan, «El sol después de la niebla », El País 31/7/1997, op. cit.

${ }^{42}$ Ibid.

${ }^{43}$ Ibid.

44 MORA, Miguel, «El biógrafo de Leopoldo M. Panero pone en duda la locura del poeta », 20/5/1999, http://elpais.com/diario/1999/05/20/cultura/927151209_850215.html, [20/3/2013].
} 
del cajero, se adapta a todos los auditorios, y tiene muchos ratos de una lucidez impresionante". 45

Le récit journalistique reprend également la dimension historique du personnage victime d'un pays oppresseur («todo ello da forma al retrato intimista de un novísimo derrotado y enfermo, y enseña un país inhóspito y opresor. » $\left.{ }^{46}\right)$, et n'omet pas non plus la mention des amours du poète: "Hay silencios significativos", dice Fernández, que cree que los grandes amores del poeta fueron Ana María Moix y Eduardo Haro Ibars ${ }^{47} .{ }^{48}$ ). De manière indirecte il est fait allusion à la bisexualité de Panero, que celui-ci revendiquera de manière subversive dans un entretien publié par El País ${ }^{49}$.

La réédition en 2001 de la célèbre anthologie de Castellet, publiée pour la première fois en 1970, donne lieu à des articles de El País consacrés au groupe des novísimos et à Leopoldo María Panero en particulier. Les novísimos se retrouvèrent pour une photo de groupe, mais celui-ci était absent: «Estaban Vázquez Montalbán, Antonio Martínez Sarrión, José Maria Álvarez, Félix de Azúa, Pere Gimferrer, Vicente Molina Foix, Guillermo Carnero y Ana María Moix. Sólo faltó el benjamín del grupo, Leopoldo María Panero $»^{50}$.

Cette anthologie fait partie de la légende des novísimos et de l'histoire de la littérature espagnole. L'article rappelle que Vázquez Montalbán considérait qu'elle était un témoignage de la poésie qui se pratiquait alors et une revendication d'un retour à la littérature. Ana María Foix insistait sur le caractère provocateur de l'anthologie et rappelait qu'une lecture préalable fut organisée en présence de José Luis Aranguren, ce que ne manque de souligner El País, journal très lié au philosophe de l'éthique. Félix de Azúa s'étonnait que tous les novísimos soient encore vivants, alors que la génération de 1968 avait subi tant de pertes : «sobre todo en una generación sesentayochesca en la que ha habido muchas bajas » ${ }^{51}$.

En 2001 un numéro du supplément culturel Babelia accorde une attention particulière à Leopoldo María Panero. On souligne la solitude du poète et les clichés attachés à sa personne : «Treinta años después, Panero es el loco oficial de la literatura española, un papel en el que él parece sentirse incómodamente a gusto, como con todos los tópicos que le han ido cayendo encima : el último poeta, el primer tabú de la literatura española... $\gg^{52}$. Le poète est décrit comme un écrivain compulsif, et El País égrène la liste de ses ouvrages ; mais le ton se fait quelque peu complaisant lorsque l'on cite ses propos d'amateur de coca-cola et que l'on tente de décrire son excentricité :

[...]" Pon también que puedo hacer un anuncio de Coca-Cola : El monstruo bebe coca-cola, glup, glup ". De cuando en cuando se queda callado largo rato y enseguida vuelve a hablar de

\footnotetext{
${ }^{45}$ Ibid.

46 Ibid.

47 Eduardo Haro Ibars, ami intime de Leopoldo María Panero, disparu en 1988, figure culte de la contreculture et du mouvement gay, pionnier de la Movida.

${ }^{48}$ Ibid.

49 « P. ¿Es homosexual?/R. No. Bisexual; es lo que irrita a los otros locos, porque son de la otra España y dicen que es más pecado ser bisexual. », Entretien avec Leopoldo María Panero, FIDALGO, Feliciano, « suicidarse es creer en la vida », El País, 30/9/1990, http://elpais.com/diario/1990/09/30/ultima/654645602_850215.html, [20/3/2013].

50 MORET, Xavier, «Los 'novísimos' se reúnen 30 años después de la famosa antología », El País, 6/3/2001, http:/ /elpais.com/diario/2001/03/06/cultura/983833208_850215.html, [20/3/2013].

${ }^{51}$ Ibid.

52 RODRÍGUEZ MARCOS, Javier, «El hombre solo », El País, 27/10/2001, http://elpais.com/diario/2001/10/27/babelia/1004139550_850215.html, [20/3/2013].
} 
Cristo y del Anticristo, su tema comodín. "La clave de mi adición-reducción teosófica es 35, la misma que la de Jesucristo. La cifra suma 8, el número que tumbado es el signo del infinito". Ha seguido las últimas noticias y no cree que Bin Laden encarne el mal absoluto. Tampoco lo tiene claro. Luego lanza una teoría maquiavélica sobre la CIA y la guerra. Finalmente musita : "Tengo miedo". 53

Babelia rend hommage au poète au travers d'articles consacrés à son œuvre, tantôt sous le titre de la rubrique "Poésie et délire », tantôt sous la rubrique "Meilleurs livres de l'année ». Les commentaires sur Panero reproduits par El País vont de la fausse hagiographie à la critique parfois sans concession. Le journal navigue de manière ambiguë d'une opinion à une autre pour que chacun y trouve son compte. L'opinion élogieuse de Gimferrer est rappelée, mais aussi la critique négative de son ami Eduardo Haro Ibars :

Nada más conocer a Leopoldo María Panero (Madrid, 1948), Gimferrer se refirió a él como "el único de nosotros que puede ser un Byron o un Shelley", y a sus instancias lo incluyó Castellet en Nueve novísimos de 1970. Por su parte, el malogrado, su antiguo compañero en los penales de Carabanchel y de Zamora donde los alojó la ley franquista "de vagos y maleantes", escribía en 1984 que "Panero es un fracaso : como poeta, como hombre, como suicida". Los ejemplos de elogios categóricos y de rechazos inapelables son tan abundantes que fomentan el deseo de fijar a Panero en el mapa de valores literarios. ${ }^{54}$

La référence au poète maudit est dite et contestée, et la reconnaissance culturelle dont il jouit est un paradoxe :

Pero ese malditismo no le ha impedido ser el primer sesentayochista en incorporarse a la nómina de clásicos de la editorial Cátedra, contar con una espléndida biografía de J. Benito Fernández que desmenuza los avatares de su ruina, e insertarse en la historia literaria, las antologías y los programas académicos, como si la cofradía de los cuerdos padeciera una variante del síndrome de Estocolmo que la empuja a integrar en el sistema a quienes pretenden dinamitarlo. ${ }^{55}$

Le poète dévoile les tabous: "Panero desvela los tabúes de la cultura: la homosexualidad, las drogas, el incesto, la blasfemia », "Allí subvierte los mitos totémicos de nuestra cultura (Cristo, la madre) y desvela a dolor vivo sus tabúes: postrimerías, homosexualidad, drogas, incesto, coprofilia, necrofilia, blasfemia $»^{56}$. Il est associé à Nerval, Poe, Rilke, Artaud, Genet, Kafka, Trakl, mais aucun Virgile ne peut le sortir de l'enfer de ses hallucinations :

Por el nexo entre arte y vida, Leopoldo María es una reliquia del tiempo en que 'el oficio de poeta implicaba llevar una vida ejemplar' (Félix de Azúa). Ello lo aproxima a Nerval, a Poe, a Rilke y, de modo más específicamente literario, a Artaud, a Genet, a Kafka, a Trakl. Espíritus contiguos, sí, pero ningún Virgilio que le guíe en los infiernos de sus alucinaciones, cuyos pasadizos tienen las salidas obturadas, y donde sólo algunos relámpagos apocalípticos alumbran el vacío. 57

\footnotetext{
${ }^{53}$ Ibid.

54 PRIETO de PAULA, ÁNGEL L., «Unos patos que vuelan sobre la nada », El País, 27/10/2001, http://elpais.com/diario/2001/10/27/babelia/1004139552_850215.html, [20/3/2013].

55 Ibid.

${ }^{56}$ Ibid.

${ }^{57}$ Ibid.
} 
L'insistance est mise sur le vide, le trou noir («agujero negro», «oquedad obstinada », " una estética cuya imposibilidad de progreso los condena a girar alrededor de $s^{1} »^{58}$ ). Seul le sujet, le poète, peut éventuellement donner une cohérence à l'oeuvre («el único aglutinante capaz de convertir las sucesivas entregas en un libro es el sujeto: un sujeto, es verdad, fragmentado en esquirlas $\iota^{59}$ ), quand il ne disparait pas derrière une écriture à deux.

Dans la rubrique Les meilleurs livres de 2001, sous le titre «Poesía más allá de los límites », un texte court encense l'œuvre de Leopoldo María Panero :

Para muchos es sólo Panero el loco, su tormentosa y personal tragedia histórica y familiar, un poeta 'maldito' que ha tenido la desgracia de nacer en España, un muerto viviente. Cuerdo o loco, qué más da, es uno de los mayores poetas de las últimas décadas y de las que vienen. El resto no importa. Este libro es su propio entramado poético, la autodefinición de un hombre solo, sin atributos, casi sin cuerpo, un hombre hecho de límites y de contornos. Ofrece en la ilegítima defensa del poema su conciencia legítima e indecible. En las cenizas hace estallar el sentido, pues para ser cenizas antes hay que haber sido llama, fuego, una única esperanza. ${ }^{60}$

Son discours est qualifié d'incohérent, mais parfois le miracle se produit («Escuchar al 'poeta loco', $[\ldots]$ es como intentar pescar perlas a pulmón libre. [...] cuando el milagro ocurre $\left.»^{61}\right)$. Panero, l'érudit, cite Lacan, Pessoa ou Genet dans la langue d'origine («Panero respondía citando a Lacan, a Pessoa o a Genet en sus idiomas de origen »). Il est celui qui a bousculé la poésie espagnole («El autor de Así se fundó Carnaby Street, obra con la que conmovió los pilares de la poesía en español hace 35 años » ${ }^{63}$ ).

\section{Le poète mythique : aura et reconnaissance des voix de l'auctoritas}

Le poète accède au statut de poète chanté en 2004 (" es un objeto tan atractivo como insólito : un cuidado disco-libro con dos CD donde los cantantes Carlos Ann y Bunbury se unen $\left.»^{64}\right)$ :

En sus libros, hemos encontrado referencias al rock, que imagino que vienen de aquella fascinación del underground español de finales de los setenta por Lou Reed y todo el rollo neoyorquino, la tríada 'sexo, drogas y rock and roll', la onda Eduardo Haro Ibars. ${ }^{65}$

\footnotetext{
${ }^{58}$ Ibid.

${ }^{59}$ Ibid.

${ }^{60}$ ORTEGA, Antonio, « Poesía más allá de los límites », El País, 29/12/2001, http://elpais.com/diario/2001/12/29/babelia/1009586365_850215.html, [20/3/2013].

${ }^{61}$ PADILLA, Andrés, "Leopoldo María Panero ajusta cuentas con sus fantasmas en un nuevo poemario », http://elpais.com/diario/2003/06/16/cultura/1055714404_850215.html, [20/3/2013].

${ }^{62}$ Ibid.

${ }^{63}$ Ibid.

${ }^{64}$ MANRIQUE, Diego A., «Bunbury y Carlos Ann cantan los atormentados versos de Panero », El País, 30/9/2004, http://elpais.com/diario/2004/09/30/espectaculos/1096495205_850215.html, [20/3/2013].

${ }^{65}$ Ibid.
} 
Le disque sera suivi d'un concert à Barcelone en 2005, sous la forme d'une sorte de "performance » pour rendre hommage au poète de la transgression : «El espectáculo y el disco libro son fruto del "interés que nos suscita Panero, un transgresor que destaca en una sociedad tan políticamente correcta como la que vivimos", afirman Ponce y Ann $»^{66}$.

Leopoldo María Panero devient le " poète mythique » ("Un día junto al mítico poeta. Cuenta chistes, piensa en la muerte y recibe mensajes telepáticos $\left.»^{67}\right)$ dans les articles du journal, qui se complaisent, cependant, à décrire un personnage insolite dont le langage savant côtoie la vulgarité dans un discours souvent incohérent, un personnage burlesque, mais entouré de jeunes et admiré : "No hay dónde sentarse en el salón de actos de la Fnac. Los fans de Panero, muy jóvenes, han venido con libros y cámaras digitales. Además de firma, quieren tener una foto con él ${ }^{68}$. Le poète rebelle, qui lève le poing sur la photo qui accompagne le texte, raconte des blagues sur les fous: «Para las fotos levanta el puño en plan comunista », «[...] ¿Te cuento un chiste de locos? »; il est profondément humain face à la mort, et il est étudié à l'université :

El hombre que ha frecuentado el abismo en la poesía, pero también en psiquiátricos y bares; el que ha escrito 43 libros. El que se estudia en la universidad como el poeta maldito español por antonomasia. [...] Él, ahora, en la terraza del Círculo de Bellas Artes, el viernes antes de comer, confiesa muy serio que le tiene miedo a la muerte. ${ }^{69}$

Le poète devient une figure canonisée que le journal El País « récupère » dans un discours le replaçant dans l'académisme et l'histoire littéraire officielle, et en premier lieu dans celle des novísimos. Lorsqu'en 2012 le festival Cosmopoética rend hommage à la génération de 1968, El País publie un article qui met en avant la présence de Leopoldo María Panero, capable de réciter de mémoire les vers de ses compagnons de poésie, et le rôle « révolutionnaire » de cette génération de poètes dans l'histoire littéraire espagnole :

José María es José María Álvarez, sentado a su lado en la terraza del hotel en que se alojan. Los dos eran unos veinteañeros cuando Josep María Castellet los incluyó en Nueve novísimos poetas españoles, la antología que en 1970 sacudió el panorama literario. Amén de certificar la defunción de la poesía social, aquella selección era un collage de surrealismo, culturalismo y cosmopolitismo. "Sólo quedamos vivos / Sobre la ciudad kaputt / Johann Sebastian Bach y yo / Y los dos muy borrachos", dicen los versos de Álvarez que Panero recita con voz nasal [...] ¿Cuál fue la aportación específica de aquel heterogéneo grupo? [...] Juan José Lanz, autor de Antología de la poesía española. 1960-1975 (Espasa), responde a la pregunta horas después: "La generación del 68 puso al día la cultura española mirando a Europa. Hicieron con la poesía lo que Luis Martín-Santos con la novela. La ruptura estética lo fue también política y social. Los novísimos fueron una de las formas del llamado franquismo pop". ${ }^{70}$

Il est habituel que le journal s'appuie sur la voix d'experts autorisés pour légitimer son discours. Dans le cas de Leopoldo María Panero, la parole est donnée à d'autres

66 HIDALGO, Luis, «Un concierto homenajea en La Paloma a Leopoldo María Panero », El País, 28/2/02005, http://elpais.com/diario/2005/02/28/catalunya/1109556449_850215.html, [20/3/2013].

${ }^{67}$ BLANCO, Sylvia, "Panero ríe, Panero teme », El País, 10/6/2007, http://elpais.com/diario/2007/06/10/madrid/1181474655_850215.html, [20/3/ 2013].

${ }^{68}$ Ibid.

${ }^{69}$ Ibid.

70 RODRÍGUEZ MARCOS, Javier, «Los novísimos vuelven a ser nuevos», El País, 5/10/2012, http://cultura.elpais.com/cultura/2012/10/04/actualidad/1349374851_959654.html, [20/3/2013]. 
novísimos, comme Vicente Molina Foix et Félix de Azúa, mais aussi à des poètes reconnus, de la même génération comme Luis Antonio de Villena ou plus jeune comme Benjamín Prado.

Molina Foix, qui fut l'ami intime de Panero, dans un texte intitulé «Bellezas del diablo », publié par El País en 1985, évoque les poètes maudits dans la lignée de Verlaine et de Rimbaud. Selon lui, Leopodo María Panero est un poète maudit «présentable » et il ironise quelque peu sur sa médiatisation. Toutefois, il lui donne le rang de plus grand poète vivant : " yo le tengo por el mayor poeta viviente de los Novísimos, y crea adicción en mucha gente; cuando yo era profesor en la universidad del País Vasco mis mejores alumnos le reverenciaban, sacándole a menudo del manicomio para invitarle a cerveza y oírle hablar como quien escucha un saber venido del otro lado. $\rangle^{11}$. Dans un texte publié en 1999, au titre évocateur "Cinema Panero $»^{72}$, Molina Foix se montre à la fois très caustique avec la «comédie » de la famille Panero et avec Leopoldo María en particulier. Pourtant son admiration pour le jeune poète est encore vive : "creo que es imposible imaginar hoy el derroche de ocurrencia verbal, de simpatía contagiosa, de claridad de ingenio aun en la turbulencia, ya incipiente, que tenía el Leopoldo María de los 18 años ». Cependant, son jugement se fait cruel lorsque sort le film Después de tantos años: "pude ver en imagen lo que la gente contaba del amigo del que me separé a mitad de los años setenta: su cultivo permanente de un gore mezclado con la escatología repulsiva del primer John Waters ${ }^{73}$. Et s'il rapporte les opinions négatives de Gil de Biedma et de Valente : «Dos poetas nada tontos, Gil de Biedma y Valente, dieron juicios crueles, el primero dictando que Leopoldo María era "un señorito sablista de Astorga", el segundo acusándole de hacer "desde la vida gestos desesperados para existir en la escritura" $\rangle^{74}$, il prend sa défense et vante son écriture poétique :

Pero los dos lo trataron poco [...] Mi teoría es que la excelente película de Chávarri, y lo que vino después, la insana necesidad de buscar sujetos expiatorios de nuestro propio desencanto, puso sobre aquellos cuatro exhibicionistas inteligentes, madre e hijos, una carga simbólica insoportable. [...] ha sido Leopoldo María, por su acusado perfil de estrambótico desatado, quien más ha atraído los medios y a las pequeñas tribus de fanáticos. Éstos al menos leen. [...] Hay que leer la obra del poeta. [...] Confieso que llevo más de 20 años huyendo de la cargante y maloliente persona de mi antiguo amigo [...] Los anticristos son una cruz. Pero en las últimas décadas nadie aquí ha puesto en práctica poética -y con el genio de muchos de sus versos- lo que él mismo escribió una vez en este periódico : la literatura no es nada si no es peligrosa. ${ }^{75}$

Lors de la publication, en 2005, de la biographie de Eduardo Haro Ibars, Eduardo Haro Ibars: los pasos del caído, de J. Benito Fernández, le même Molina Foix, prend ses distances avec le personnage Panero : «Leopoldo María, amigo muy íntimo y admirado del que, al convertirse en los últimos años en un ejecutivo de la transgresión más estéril y

\footnotetext{
${ }^{71}$ MOLINA FOIX, Vicente, « Bellezas del diablo », El Pais, 22/6/1985, http://elpais.com/diario/1995/06/22/cultura/803772001_850215.html, [20/3/ 2013].

72 MOLINA FOIX, Vicente, « Cinema Panero », El País, 14/7/1999, http://elpais.com/diario/1999/07/14/cultura/931903203_850215.html, [20/3/ 2013].

75 Ibid. et quant à la citation de Panero, on la trouvera dans : PANERO, Leopoldo María, «Acerca de la literatura », El País, 20/6/1984, http://elpais.com/diario/1984/06/20/cultura/456530403_850215.html, [20/3/2013].
} 
plasta, huyo como de la peste, utilizando la palabra 'artaudiana' que a él le tiene que gustar. $»^{76}$.

Un hommage appuyé est rendu à Panero par Félix de Azúa, lors de la publication du numéro de Babelia en octobre 2001. Dans une tribune intitulée «Poeta », le novísimo souligne la difficulté de l'écriture poétique, donnée à quelques êtres rares, qui ont accès, ou pris le risque d'accéder, à la folie de la poésie. Lui-même s'en exclut, mais il revendique le statut de poète pour Leopoldo María Panero :

Pero la poesía es otra cosa. No sólo es distinta de la novela, también es distinta de lo que se suele entender por 'literatura'. Puede uno leer cuatrocientos libros de versos sin rozar la poesía. [...] El otro día, por ejemplo, la poesía se filtraba en las páginas de Babelia dedicadas a Leopoldo María Panero.

Panero, que vive desde hace décadas en los manicomios, no está loco. Si alguien está loca es la poesía. Pero a Panero lo eligió la poesía y se lo llevó con ella a su lugar de residencia. Por eso, en la entrevista de Rodríguez Marcos, a veces hablaba Panero y a veces hablaba la poesía. Panero, muy sensato, decía: "Creo en la poesía técnicamente bien escrita", pero la poesía decía : "Aplasto los cigarrillos en el suelo, como si fueran niños". Confesaba Panero: "Quiero ser un hombre común", pero la poesía confesaba : "Desde hace tiempo tengo una mujer que se llama orujo". Preguntado por sus libros, decía Panero : "De esos libros yo no he visto un duro", pero la poesía decía : "Soy la ceniza de un poema en que no creo". Afirmaba Panero: "Más solo que yo, imposible", pero afirmaba la poesía : "Resucitar y ser resucitado, y volver de la nada sin nada de abrigo". Y así sucesivamente.

La poesía está loca porque su alucinación no coincide con la locura de quienes somos razonables. $\mathrm{O}$, más exactamente, estamos instalados en una locura incompatible con la locura de la poesía. [...] En consecuencia, los cobardes, o, siendo magnánimos, los prudentes, nos ponemos a salvo de la poesía. ${ }^{77}$

Lorsque la maison d'édition Visor publie en 2001 Poesía completa 1970-2000, le jeune poète Benjamín Prado défend avec ferveur l'écriture du «poète le plus original des 40 dernières années » pour qu'il soit lu par tous :

[...] sigue escribiendo poemas de una belleza cegadora. Hace poco lo visité en el hospital. Está muy deteriorado, su ropa está raída, tiene la delgadez de quien parece estar en su cuerpo como al borde de un abismo. [...] parece un ser improbable, un mito del pasado. Resucítenlo leyendo su Poesía completa 1970-2000. Conozcan al gran poeta vivo de esta ciudad. ${ }^{78}$

En 2004 est publié par Hiperión Esquizofrénicas o la balada de la lámpara azul de Leopoldo María Panero. Dans Babelia le poète Luis Antonio de Villena sauve l'écriture poétique, tout en regrettant l'esthétique limitée de l'écriture imprécatoire de l'homme Panero brisé : «Leopoldo es un poeta -y un hombre- quebrado. Lleno de fulgores y de trágica hondura es hoy por hoy (y las razones son evidentes) incapaz de superar la limitada estética del fragmento imprecatorio. Leopoldo se repite y duele en la carne del lector, que mira la lucha de Jacob y el ángel en su persona ${ }^{79}$.

\footnotetext{
${ }^{76}$ MOLINA FOIX, Vicente, «Lo que vio Haro Ibars », El Pais, 3/6/2005, http://elpais.com/diario/2005/06/03/madrid/1117797861_850215.html, [20/3/2013]. 77 AZÚA, Félix, « Poeta », El País, 31/10/2001, http://elpais.com/diario/2001/10/31/ultima/1004482802_850215.html, [20/3/2013]. 78 PRADO, Benjamín, « Panero el loco », El País, 20/9/2001, http://elpais.com/diario/2001/09/20/madrid/1000985058_850215.html, [20/3/2013]. ${ }^{79}$ VILLENA, Luis de, «Invocando a la nada », El País, 13/11/2004,
} 
La parole a été donnée assez régulièrement à Leopoldo María Panero lui-même, au travers de propos cités, d'articles ou d'entretiens. Il s'est exprimé sur la littérature, la psychanalyse, la psychiatrie, la société, la politique. Trois entretiens ont été réalisés par El País. Le premier, sous le titre "Suicidarse es creer en la vida $»^{80}$, questionne le poète sur les parents, l'éducation, Dieu, la poésie, la folie, et semble s'adresser plutôt à la personne médiatique. Le second, publié dans Babelia, auquel fait référence Azúa ${ }^{81}$, "Seré un monstruo pero no estoy loco $»^{82}$, interroge plutôt l'œuvre et les goûts littéraires, et s'adresse au poète érudit. Le troisième, «España es la que está loca, no yo » ${ }^{83}$, insiste sur la folie et l'écriture, mais évoque un faux fou, savant et sarcastique. Quelques vers peu subversifs ont été cités. Des extraits un peu plus longs de Pruebas de vida. Autobiografía apparaissent dans le numéro du 27 octobre 2001 de Babelia sous la rubrique "Poesía y Delirio » ${ }^{84}$ et une bibliographie exhaustive est publiée.

Si le poète est reconnu, il reste un personnage qui exerce une attraction-répulsion pour nombre de chroniqueurs. Ces opinions diverses permettent à El País de prendre des distances avec la personnalité controversée du poète tout en reconnaissant la dimension de son œuvre poétique. Lorsque Panero meurt en mars $2014^{85}$, les superlatifs ne manquent pas pour qualifier le poète mythique, mais, avec la marginalité, la référence majeure est celle de la folie. La folie inquiète mais elle est une source médiatique intarissable et permet de lire avec une certaine distance une poésie trop subversive ou bouleversante. La figure rebelle et souffrante de Leopoldo María Panero dérange une Espagne démocratique qui croit avoir surmonté ses tabous.

Lo he dicho muchas veces : que no usen mi torpe biografía para juzgarme. Todo ese rollo vendrá de que tiene morbo que esté en un manicomio, digo yo. Estoy harto de los malditos, harto de ser el loco, harto de ser Leopoldo María Panero. Quiero ser un hombre común. Si me dieran el Nobel haría un discurso en inglés titulado Against Spain, Contra España. Y me iría a vivir a París. 86

\footnotetext{
http://elpais.com/diario/2004/11/13/babelia/1100307017_850215.html, [20/3/2013].

${ }^{80}$ FIDALGO, Feliciano, 30/9/1990, « Suicidarse es creer en la vida », El País, 30/09/1990, http://elpais.com/diario/1990/09/30/ultima/654645602_850215.html, [20/3/2013].

81 Cf. supra

82 «Seré un monstruo pero no estoy loco », El País, 27/10/2001, http://elpais.com/diario/2001/10/27/babelia/1004139550_850215.html, [20/3/2013].

83 «España es la que está loca, no yo », El País, 9/8/2005,

http://elpais.com/diario/2005/08/09/ultima/1123538401_850215.html, [20/3/2013].

84 «Pruebas de vida. Autobiografía», El País, 27/10/2001,

http://elpais.com/diario/2001/10/27/babelia/1004139551_850215.html, [20/3/2013].

${ }^{85}$ MANRIQUE SABOGAL, Winston, INTXAUSTI, Aurora, « Muere Leopoldo María Panero, poeta de los Nueve Novísimos », El País, 6/3/2014,

http://cultura.elpais.com/cultura/2014/03/06/actualidad/1394093486_474925.html, [12/3/2014],

RODRÍGUEZ MARCOS, Javier, «Leopoldo María Panero, maldito sea »,

http://cultura.elpais.com/cultura/2014/03/06/actualidad/1394106885_605843.html, [12/3/2014].

86 "Seré un monstruo pero no estoy loco », El País, 27/10/2001,

http://elpais.com/diario/2001/10/27/babelia/1004139550_850215.html, [20/3/2013].
} 